\title{
Raphe GABAergic Neurons Mediate the Acquisition of Avoidance after Social Defeat
}

\author{
Collin Challis, ${ }^{1,2}$ Janette Boulden, ${ }^{1}$ Avin Veerakumar, ${ }^{1}$ Julie Espallergues, ${ }^{1}$ Fair M. Vassoler, ${ }^{1,2}$ R. Christopher Pierce, ${ }^{1,2}$ \\ Sheryl G. Beck, ${ }^{2,3}$ and Olivier Berton ${ }^{1,2}$ \\ ${ }^{1}$ Department of Psychiatry and ${ }^{2}$ Neuroscience Graduate Group, University of Pennsylvania Perelman School of Medicine, Philadelphia, Pennsylvania 19104, \\ and 'Department of Anesthesiology, Children's Hospital of Philadelphia and University of Pennsylvania Perelman School of Medicine, Philadelphia, \\ Pennsylvania 19104
}

Serotonin (5-HT) modulates neural responses to socioaffective cues and can bias approach or avoidance behavioral decisions, yet the cellular mechanisms underlying its contribution to the regulation of social experiences remain poorly understood. We hypothesized that GABAergic neurons in the dorsal raphe nucleus (DRN) may participate in socioaffective regulation by controlling serotonergic tone during social interaction. We tested this hypothesis using whole-cell recording techniques in genetically identified DRN GABA and 5-HT neurons in mice exposed to social defeat, a model that induces long-lasting avoidance behaviors in a subset of mice responsive to serotonergic antidepressants. Our results revealed that social defeat engaged DRN GABA neurons and drove GABAergic sensitization that strengthened inhibition of 5-HT neurons in mice that were susceptible, but not resilient to social defeat. Furthermore, optogenetic silencing of DRN GABA neurons disinhibited neighboring 5-HT neurons and prevented the acquisition of social avoidance in mice exposed to a social threat, but did not affect a previously acquired avoidance phenotype. We provide the first characterization of GABA neurons in the DRN that monosynaptically inhibit 5-HT neurons and reveal their key role in neuroplastic processes underlying the development of social avoidance.

\section{Introduction}

Studies in numerous species support a conserved role for the neurotransmitter serotonin (5-HT) in the modulation of social approach or avoidance behaviors (Canli and Lesch, 2007). In humans, pharmacological manipulations of 5-HT have been shown to shift appraisal and responses to social cues along an "affiliative-aggressive" axis (Young, 2013), with 5-HT depletion consistently facilitating socially defensive responses such as avoidance and aggression (Liu et al., 2010; Passamonti et al., 2012). In contrast, enhancement of 5-HT has been shown to

Received June 4, 2013; revised July 11, 2013; accepted July 19, 2013.

Author contributions: C.C., J.E., S.G.B., and 0.B. designed research; C.C., J.B., and A.V. performed research; F.M.V. and R.C.R. contributed unpublished reagents/analytic tools; C.C. analyzed data; C.C., S.G.B., and O.B. wrote the paper.

This work was supported by the National Institutes of Health (National Institute of Mental Health Grants \#MH087581 to 0.B. and Grants \#MH0754047 and \#MH089800 to S.G.B. and National Research Service Award Grants $\#$ \#32MH014654 and \#F31MH097386 to C.C.), the International Mental Health Research Organization (0.B.), the National Alliance for Research in Schizophrenia and Affective Disorders (0.B.), and the National Institute on Drug Abuse (Grants DA18678 and DA22339 to R.C.R.). We thank Dr. Mark Alter for providing us with GAD1-GFP mice, and Dr. Irwin Lucki for proofreading the manuscript.

The authors declare no competing financial interests.

Correspondence should be addressed to either of the following: Olivier Berton, Department of Psychiatry, University of Pennsylvania Perelman School of Medicine, TRL, 125 S. 31st Street, Philadelphia, PA 19104, E-mail: bertonol@mail.med.upenn.edu; or Sheryl Beck, Department of Anesthesiology, Children's Hospital of Philadelphia, ARC, Room 402A, 3615 Civic Center Boulevard, Philadelphia, PA 19104, E-mail: becks@email.chop.edu.

J. Espallergues' present address: Department of Neurobiology, Inserm Unité 661, Institut de génomique fonctionnelle, Montpellier, France.

F. M. Vassoler's present address: Department of Biomedical Sciences, Cummings School of Veterinary Medicine, Tufts University, Peabody Pavilion, 200 Westborough Road, Grafton, MA 01536.

DOI:10.1523/JNEUROSCI.2383-13.2013

Copyright $\odot 2013$ the authors $\quad 0270-6474 / 13 / 3313978-11 \$ 15.00 / 0$ induce rapid positive shifts in the perception of socioaffective stimuli, often promoting affiliation and dominance (Raleigh et al., 1991; Bilderbeck et al., 2011). These 5-HT-mediated effects could contribute to the therapeutic action of monoaminergic antidepressants by facilitating interpersonal function and promoting resilience to psychosocial threats such as social rejection, a common precipitant of the onset or relapse of affective disorders in vulnerable individuals (Charuvastra and Cloitre, 2008; Slavich et al., 2010; Cusi et al., 2012; Meyer-Lindenberg and Tost, 2012; Phan et al., 2013; Hames et al., 2013). Despite the existence of a large body of research on 5-HT, surprisingly little is known about the precise circuitry through which 5-HT neurons regulate cognitive processes associated with social approach or avoidance behaviors in mammals. Most ascending 5-HT neurons are found in the median and dorsal raphe nuclei (DRN) of the brainstem; however, these two nuclei are neuronally heterogeneous and a large proportion of raphe neurons are nonserotonergic (Bang and Commons, 2012; Bang et al., 2012). Local GABAergic neurons in the DRN are thought to provide an inhibitory relay for converging inputs that exert top-down control over 5-HT function (Freedman et al., 2000; Celada et al., 2001; Chiba et al., 2001; Varga et al., 2001; Varga et al., 2003; Amat et al., 2005). Pharmacological evidence further suggests that modulating GABA activity in the DRN has a dramatic impact on affiliative or aggressive behaviors (Takahashi et al., 2010; Takahashi et al., 2012); however, our understanding of these mechanisms on a microcircuit level remains limited.

To analyze the interplay between GABAergic and 5-HT neurons in the DRN microcircuit and their regulation during social- 
stress-adaptive processes, we used transgenic mouse lines for genetic identification of these neuronal populations and selective targeting of optogenetic effectors for functional studies. We examined these mechanisms in the context of social defeat, a model of psychosocial stress that results in long-lasting social avoidance and is sensitive to the effects of antidepressants (Berton et al., 2006; Tsankova et al., 2006). Our results provide direct functional evidence for the existence of DRN GABA neurons that monosynaptically inhibit 5-HT neurons and implicate experience-driven neuroplastic adaptations in these GABA neurons during the development of social avoidance. By providing novel insights about the cellular underpinnings of social approach or avoidance decision biases, our results have important implications for the understanding and treatment of affective disorders.

\section{Materials and Methods}

Animal subjects. Eight- to 12-week-old male mice bred onto a C57BL/6 background were used for all experiments. Mice were housed on a $12 \mathrm{~h}$ light/dark cycle with food and water available ad libitum. All studies were conducted according to protocols approved by the University of Pennsylvania institutional animal care and use committee. All procedures were performed in accordance with institutional guidelines. To generate a mouse line with fluorescently labeled GAD65-containing GABAergic or serotonergic neurons, male knock-in GAD2-Cre mice (Gad2 ${ }^{\mathrm{tm} 2(\mathrm{cre}) \mathrm{Zjh}} / \mathrm{J}$; JAX stock number 010802; Taniguchi et al., 2011) or BAC transgenic Pet1-Cre mice (B6.Cg- $\mathrm{Tg}$ (Fev-cre) 1Esd/J; JAX stock number 012712; Scott et al., 2005) were respectively crossed to floxed-stop controlled tdTomato (RFP variant) mice (B6.Cg-Gt(ROSA)26Sor ${ }^{\text {tm9(CAG -tdTomato)Hze/ }}$ J; JAX stock number 007908; Madisen et al., 2010) to achieve fluorescent labeling of Cre-containing cells. We also obtained BAC-transgenic GAD1-GFP mice (CB6-Tg(Gad1-EGFP)G42Zjh/J; JAX stock number 007677; Chattopadhyaya et al., 2004) for fluorescent labeling of GAD67containing GABAergic neurons. In our behavioral experiments, we used the GAD2-Cre mice and the generated GAD2-tdTomato and Pet1$t d$ Tomato mice, with the exception of the limited sensory contact defeat experiment, for which we used C57BL/6J (JAX stock number 000664) mice. All strains were procured from The Jackson Laboratory.

Viruses and surgery. To express optogenetic or fluorescent proteins in GABAergic neurons, adeno-associated virus (AAV) vectors were produced by and purchased from the University of Pennsylvania vector core (Philadelphia, PA) and injected into GAD2-Cre mice. In this work, we used AAVs for the Cre-inducible expression of the inhibitory optogenetic probe Archaerhodopsin (AAV2/9.flex.CBA.Arch-GFP.W.SV40, catalog \#22222; Addgene) and Cre-inducible expression of the fluorescent protein tdTomato (AAV2/1.CAG.FLEX.tdTomato.WPRE.bGH, catalog \#864; Allen Institute ). For tracing of excitatory vmPFC terminals in the DRN, we used an AAV for the CaMKIIa-driven expression of YFP fused to Channelrhodopsin (AAV2/9.CaMKII.ChR2-YFP.SV40, Stanford University, Stanford, CA; Mattis et al., 2012).

For viral injections, mice were anesthetized with isoflurane and stereotaxically injected unilaterally in the DRN (from lambda, in mm: $0.0 \mathrm{AP}$, $+0.8 \mathrm{ML},-3.3 \mathrm{DV}, 15^{\circ}$ angle) or prelimbic region of the vmPFC (from bregma, in $\mathrm{mm}:+1.8 \mathrm{AP},+0.8 \mathrm{ML},-2.7 \mathrm{DV}, 15^{\circ}$ angle) with $1 \mu \mathrm{l}$ of virus. Viral yields (in GC) were $6.962 \times 10^{11}$ for Arch-GFP, $2.049 \times 10^{12}$ for tdTomato, and $4.347 \times 10^{12}$ for CaMKIIa-ChR2-YFP. Social defeat began 4 weeks after surgery for noncannulated mice to allow time for recovery and viral expression.

For in vivo optical stimulation, precut guide cannulae (Plastics One) targeting the DRN were secured to the skull using the coordinates mentioned above. Cannulae were secured using stainless steel skull screws and acrylic cement. A fitted dust cap dummy was secured atop the guide cannula and mice were placed back in their home cages and allowed 6 weeks to recover. Body weight and behavior were monitored during recovery. Three days before the start of experiment, a homemade fiber optic with ferrule connector (described below) was inserted into the guide cannula and secured with acrylic cement.
Preparation of optical fibers. A $200 \mu \mathrm{m}$ core, 0.37 numerical aperture (NA) standard multimode fiber (Thorlabs) was stripped of cladding, passed through a $230 \mu \mathrm{m}$ multimode ceramic zirconia ferrule (Precision Fiber Products), and secured in place using fiber optic connector epoxy (Fiber Instrument Sales). Ferrules were then polished and cut to length to target the DRN, tested for light output, and sterilized with $70 \%$ ethanol.

Repeated social defeat training and interaction testing. The social defeat paradigm consisted of alternating periods of physical contact with a trained CD1 aggressor (5 min) and protected sensory contact via separation by a perforated Plexiglas partition $(24 \mathrm{~h})$. In trials in which sensory contact was limited, mice were separated for only $20 \mathrm{~min}$ before being returned to their home cages overnight. This continued for 10 consecutive days, with exposure to a novel aggressor each day, as described previously (Golden et al., 2011; Espallergues et al., 2012). Control animals were housed in similarly partitioned cages with a paired mouse from the same genotype and switched to opposite sides of the partition daily. On day 11, social approach or avoidance behavior toward an unfamiliar CD1 social target was assessed in a two-trial social interaction task. In the first 2.5 min trial ("no target"), experimental mice explored a dimly lit (55 lux) open-field arena containing an empty wire mesh cage on one edge of the arena (Fig. 6A). In the second 2.5 min trial ("target present"), experimental mice were reintroduced to the arena, now with an unfamiliar CD1 aggressor positioned in the mesh cage. TopScan video tracking software (CleverSys) was used to measure the time spent in the interaction zone surrounding the target box. Interaction ratios (IRs) were calculated as the time spent in the interaction zone in the "target present" condition as a percentage of the time spent in the zone in the "no target" condition. Susceptible (SUS, IR < 100) and Resilient (RES, IR > 100) mice were determined as described previously (Krishnan et al., 2007).

Open field test and elevated plus maze. For the open field test (OFT), mice were placed in the center of an arena identical to that which was used for the social interaction test described above, but lacking the mesh wire cage. The test lasted for $5 \mathrm{~min}$ and TopScan video-tracking software was used to determine the amount of time spent in the center of the arena. OFT was conducted under 55 lux illumination. The elevated plus maze (EPM) consisted of 2 perpendicular, intersecting platforms, each $7.6 \mathrm{~cm}$ wide and $60 \mathrm{~cm}$ long, positioned on a pedestal $30 \mathrm{~cm}$ from the floor. TopScan was also used to measure the time spent and number of entries in open and closed arms. Illumination of the open arms of the EPM was measured to be 10 lux.

Immunohistochemistry. Animals were transcardially perfused with $4 \%$ paraformaldehyde and brains were processed for standard single or dual immunolabeling methods as described previously (Espallergues et al., 2012). For detection of $c F o s$, we used an affinity purified rabbit polyclonal antibody raised against the $\mathrm{N}$ terminus of human $c$ Fos (SC-52; Santa Cruz Biotechnology). To label 5-HT neurons, we used a sheep anti-TPH antibody (AB1541; Millipore). For dual labeling of $c F o s$ and $\Delta F o s B$, we used affinity-purified goat anti-cFos (SC-52; Santa Cruz Biotechnology) and rabbit anti- $\Delta$ FosB (SC-48; Santa Cruz Biotechnology) antibodies. To enhance GFP expression, we used a chicken anti-GFP antibody (GFP-1020; Aves Laboratories). Primary antibodies were detected using fluorescent secondary antibodies obtained from Jackson ImmunoResearch Laboratories. For the processing of the brain slices from electrophysiology, we used mouse anti-TPH (T067; SigmaAldrich), along with either a donkey anti-mouse Alexa Fluor 488 (A21202; Invitrogen) or donkey anti-mouse Alexa Fluor 647 (A31571; Invitrogen), and the biocytin was visualized by streptavidin Alexa Fluor 647 (S32357; Invitrogen) or streptavidin 594 (S11227; Invitrogen).

Cell counting. To quantify cFos or $\Delta F o s B$ colocalization with $t d T o$ mato $^{+}$or $\mathrm{GFP}^{+}$neurons, $30 \mu \mathrm{m}$ serial sections of the DRN were collected every $120 \mu \mathrm{m}$ between $-4.36 \mathrm{~mm}$ and $-4.96 \mathrm{~mm}$ from bregma. Slices were stained for $c$ Fos or $\Delta$ Fos $B$ and labeled neurons were manually counted in the DRN of each section. Colocalization with tdTomato or GFP was defined as nuclear localization of the $c F o s$ or $\triangle F o s B$ signal and was counted manually. There were no significant variations in the total numbers of $t$ dTomato ${ }^{+}$or $\mathrm{GFP}^{+}$cells within each strain.

Electrophysiology. Brain slices were prepared as described previously (Crawford et al., 2010; Calizo et al., 2011; Espallergues et al., 2012; Craw- 
ford et al., 2013). The $200 \mu \mathrm{m}$ coronal slices containing DRN were placed in aCSF containing the following (in $\mathrm{mm}$ ): $124 \mathrm{NaCl}, 2.5 \mathrm{KCl}, 1.25$ $\mathrm{NaH}_{2} \mathrm{PO}_{4}, 2.0 \mathrm{MgSO}_{4}, 2.5 \mathrm{CaCl}_{2}, 10$ dextrose, and $26 \mathrm{NaHCO}_{3}$ at $37^{\circ} \mathrm{C}$ aerated with $95 \% \mathrm{O}_{2} / 5 \% \mathrm{CO}_{2}$. After $1 \mathrm{~h}$, slices were kept at room temperature. Tryptophan $(2.5 \mathrm{~mm})$ was included in the holding chamber to maintain 5-HT synthesis, but was not in the aCSF perfusing the slice in the recording chamber. Individual slices were placed in a recording chamber (Warner Instruments) and perfused with aCSF at $2 \mathrm{ml} / \mathrm{min}$ maintained at $32^{\circ} \mathrm{C}$ by an in-line solution heater (TC-324; Warner Instruments). Neurons were visualized using a Nikon E600 upright microscope fitted with a $60 \times$ water-immersion objective and targeted under differential interference contrast or fluorescent filters. Resistance of electrodes was approximately $8-10 \mathrm{M} \Omega$ when filled with a recording solution composed of the following (in $\mathrm{mm}$ ): $130 \mathrm{~K}$-gluconate, $5 \mathrm{NaCl}, 10 \mathrm{Na}$ phosphocreatine, $1 \mathrm{MgCl}_{2}, 0.02 \mathrm{EGTA}, 10 \mathrm{HEPES}, 2 \mathrm{MgATP}$, and 0.5 $\mathrm{Na}_{2} \mathrm{GTP}$ with $0.1 \%$ biocytin and a $\mathrm{pH}$ of 7.3 . Whole-cell recordings were obtained using a Multiclamp 700B amplifier (Molecular Devices). Cell characteristics were recorded using current-clamp techniques, as described previously (Crawford et al., 2010; Espallergues et al., 2012). Signals were collected and stored using Digidata 1320 analog-to-digital converter and pClamp 9.0 software (Molecular Devices). Collection of EPSC data was as described previously (Crawford et al., 2011) and performed with bath application of $20 \mu \mathrm{M}$ bicuculline to block GABA synaptic activity. Collection of IPSC data was performed as described previously (Crawford et al., 2013), with bath application of $20 \mu \mathrm{M}$ DNQX to block AMPA/kainate synaptic activity. All drugs were made in stock solutions, diluted on the day of the experiment, and added directly to the ACSF.

Electrophysiology data analysis. Cellular characteristics were analyzed using Clampfit 9.0 (Molecular Devices). Synaptic properties were analyzed using MiniAnalysis (Synaptosoft) as described previously (Crawford et al., 2011; Crawford et al., 2013). Frequency-intensity plots were generated by measuring the number of action potentials generated by depolarizing current steps ranging from 0 to $100 \mathrm{pA}$ for GAD2-tdTomato and from 0 to $120 \mathrm{pA}$ for Pet1-tdTomato neurons in $20 \mathrm{pA}$ increments. The average firing rate for each condition was determined by the number of action potentials generated over the $500 \mathrm{~ms}$ current pulse. Synaptic events were analyzed using parameters optimized for each cell with the detection threshold set beyond the maximum values of the all points noise histogram for a portion of the trace containing no detectable synaptic events. This threshold generally ranged from 5 to $8 \mathrm{pA}$. MiniAnalysis generates a summary table containing the mean and median values for the frequency, amplitude, rise time (10-90\%), decay time, and event half-width (50\%). For each cell, at least 200 events were chosen at random, filtered manually to exclude multiple peaks, and then combined to obtain an averaged EPSC or IPSC for each cell to obtain values for decay time, event area, and event time half-width. The Kolmogorov-Smirnov test was used to determine whether the histograms and cumulative probability plots of the synaptic activity characteristics were different between each group. Additional statistical analysis is described below. Data are reported as means \pm SEM.

Optical stimulation. For in vivo stimulation, mice with previously implanted fiber optic ferrules were connected to a $200 \mu \mathrm{m}, 0.37 \mathrm{NA}$ patch cord via a zirconia sleeve that was then connected to a diode-pumped solid-state laser through an FC/PC adaptor and rotary joint. We used a yellow (561 nm, GR-561-00100-CWM-SD-05-LED-F) diode-pumped solid-state laser obtained from OEM Laser Systems. For stimulation of Arch-expressing GAD2 neurons in the DRN, we performed constant yellow light stimulation for $20 \mathrm{~min}$. Power output was determined using an optical sensor (Thorlabs) to be approximately $10 \mathrm{~mW}$. Intensity was calculated using a model predicting irradiance in mammalian tissues (http://www.stanford.edu/group/dlab/cgi-bin/graph/chart.php). From a $200 \mu \mathrm{m}$ tip, the estimated intensity was $7.05 \mathrm{~mW} \mathrm{~mm}^{-2}$ for yellow laser stimulation.

For stimulation of brain slices expressing Arch in GAD2 neurons, a prepared $200 \mu \mathrm{m}$ core, 0.37 NA standard multimode fiber was lowered into the recording chamber and submerged below the ACSF. The tip of the fiber was positioned $\sim 1 \mathrm{~mm}$ from the $\mathrm{DRN}$, illuminating the entire region. Constant $10 \mathrm{~mW}$ yellow light stimulation was performed in $5 \mathrm{~s}$ epochs every $20 \mathrm{~s}$. Laser intensity was estimated to be $10.01 \mathrm{~mW} \mathrm{~mm}^{-2}$.

Data analysis and statistics. For multiple group comparisons, all variables were distributed normally based on Bartlett's test and analyzed using parametric statistics (i.e., one- or two-way ANOVAs, between group or with repeated measures, followed by Fisher's PLSD test as appropriate). Comparisons between two groups were performed using Student's $t$ test. Statistical analysis was performed using Statistica (StatSoft). Statistical significance was defined as $p<0.05$. All data are presented as means \pm SEM. Outlying values (3 SDs from the mean) were excluded from group means.

\section{Results}

Induction of FOS proteins in the DRN by social defeat predominates in GAD2-containing GABA neurons

Prior studies using immediate early gene mapping have documented the activation of DRN neurons by stress (Roche et al., 2003; Paul et al., 2011). Our previous multilabel studies combining in situ hybridization detection of cell-type-specific mRNA markers and immunohistochemical labeling of FOS family proteins showed that 5-HT neurons represent only a minority $(<10 \%)$ of DRN cells undergoing FOS-mediated neuroadaptations after repeated exposure to two models of depression (learned helplessness and social defeat), whereas a comparatively higher proportion of FOS-labeled cells expressed GAD mRNA (Berton et al., 2007). Here we investigated whether transgenic mouse lines with genetically labeled neurons would reveal a comparable distribution of $c$ Fos in the DRN after being subjected to social defeat. To assess the engagement of two major GABA neurons subtypes (i.e., $G A D 1^{+}$and $G A D 2^{+}$) in the $\mathrm{DRN}$, we examined defeat-induced $c F o s$ in GAD1-GFP BAC transgenic mice that have fluorescently labeled GAD67 neurons (Chattopadhyaya et al., 2004; Fig. 1A) and also GAD2-tdTomato mice that were generated by crossing mice expressing Cre recombinase at the GAD2 (GAD65) locus (Taniguchi et al., 2011) with a double-floxed $t d$ Tomato reporter strain (Madisen et al., 2010; Fig. 1D). A Pet1tdTomato line was similarly generated to label 5-HT neurons (Scott et al., 2005; Fig. 1G).

We subjected cohorts of adult male mice from these three lines to 10 consecutive days of social defeat, as described previously (Berton et al., 2006; Golden et al., 2011). No differences were observed among GAD1-GFP, GAD2-tdTomato, and Pet1tdTomato lines regarding their expression of social avoidance after defeat (data not shown). Twenty-four hours after testing, mice were exposed to an additional social defeat experience and perfused $1 \mathrm{~h}$ later. DRN slices from each strain were immunolabeled for $c F o s$ (Fig. $1 B, E, H$ ). A significant increase in total number of $c$ Fos-labeled cells was observed in the DRN of defeated mice versus undefeated controls (two-way ANOVA, main effect of defeat, $F_{(1,26)}=60.22$, $p<0.001$; for GAD1-labeled mice $n=$ 3 for undefeated, 3 for defeated; for GAD2-labeled mice $n=4$ for undefeated, 7 for defeated; for Pet1-labeled mice $n=3$ for undefeated, 7 for defeated), without a significant difference between strains (Fig. $1 J$ ). Topographic distribution of $c$ Fos after repeated social defeat, which was circumscribed to the ventrolateral portions of the DRN where 5-HT cells are sparse, resembled the previously reported distribution of $\triangle F O S B$, which is another FOS variant induced by stress and is particularly enriched in DRN substance P neurons (Berton et al., 2007). Because topographical similarity suggests that the same cell population may be expressing both $c F o$ and $\Delta F o s B$ after social defeat, we examined the level of colocalization between these two proteins in DRN neurons using immunolabeling. We found that $77.3 \pm 6.9 \%$ of $c$ Fos ${ }^{+}$cells also expressed $\Delta$ FosB $(n=3)$, making it likely that the defeat- 

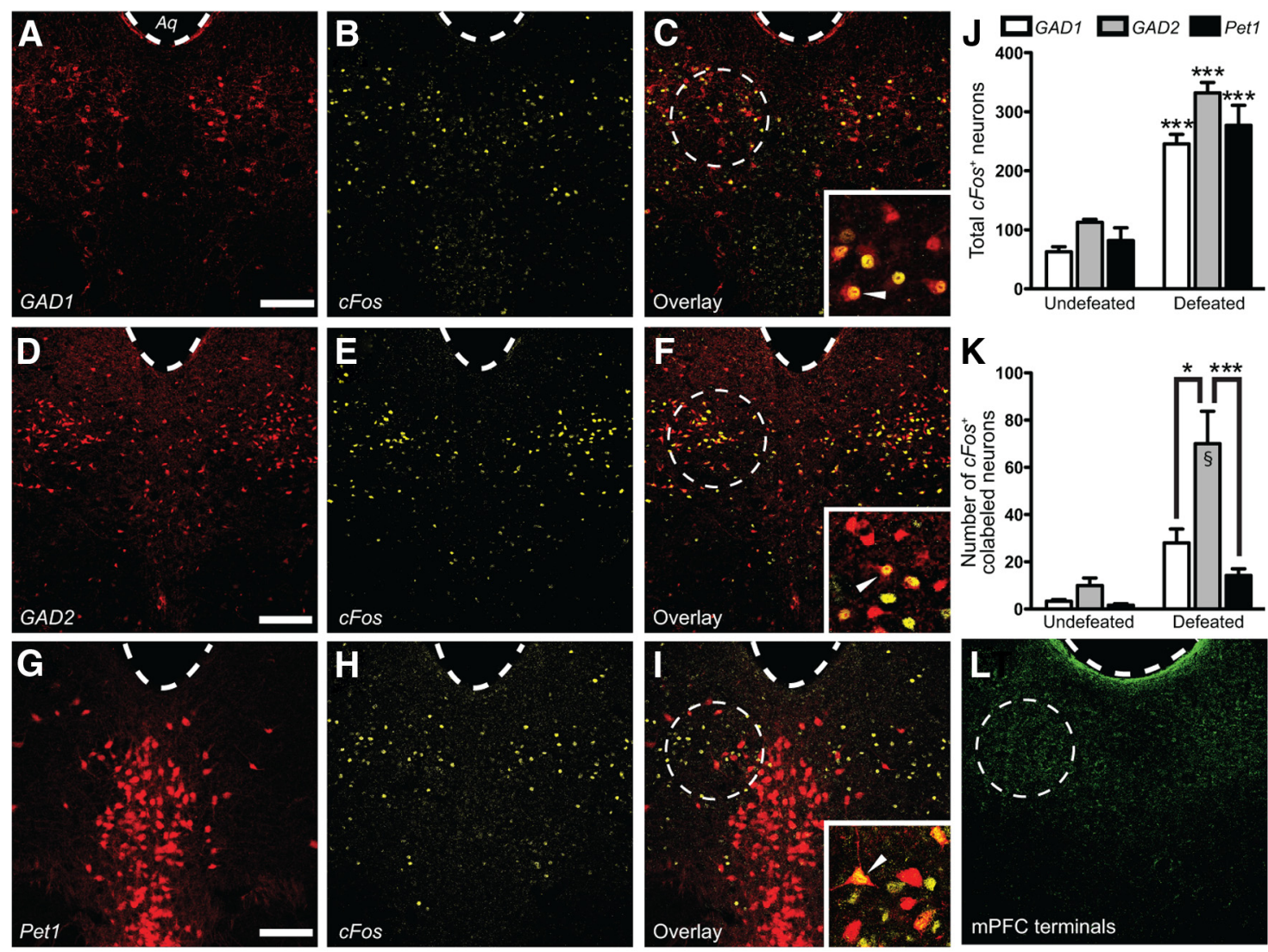

Figure 1. Social defeat-induced CFos expression predominated in GAD2-expressing GABAergic neurons in the DRN. $\boldsymbol{A}-\boldsymbol{I}$, Distribution of defeat-induced (Fos in the DRN of GAD1-GFP mice with fluorescently tagged $G A D 67{ }^{+}$GABA neurons (A-C; pseudocolored red for consistency), GAD2-tdTomato mice with fluorescently tagged GAD65 ${ }^{+}$GABA neurons (D-F), or Pet1-tdTomato mice with fluorescently tagged 5-HT neurons $(\mathbf{G}-\mathbf{I})$. Note the striking overlap between CFos- and GAD2-labeled GABAergic neurons. Aq, aqueduct. Scale bar, $50 \mu \mathrm{m}$. High-magnification (63X) images depicting cFos colocalization with fluorescently labeled neurons can be found in the insets of $C, F$, and $I$. Examples of colocalized neurons are marked with a solid arrowhead. $J$, Lack of overall difference in total number of $\mathrm{CFOS}^{+}$-labeled DRN neurons after social defeat among GAD2-tdTomato, Pet1-tdTomato, and GAD1-GFP mouse lines. Within strains, there was a significant increase in total CFos $^{+}$neurons after defeat compared with controls (two-way ANOVA, Fisher's post hoc; GAD2 ${ }^{* * *} p<0.001$; Pet1 ${ }^{* * *} p<0.001 ; G A D 1{ }^{* * *} p<0.001$; per genotype $n=3-5$ for undefeated, $n=3-7$ for defeated). $K$, Quantitation of $(F$ os colocalization in GABA and 5 -HT neurons of control and defeated mice. The defeated mice demonstrated significantly higher GABAergic $C F 0$ s induction versus controls. Overall cFos induction in GAD2-labeled neurons was significantly greater than in Pet1- or GAD1-labeled neurons (two-way ANOVA, Fisher's post hoc; GAD2/defeat vs GAD1/defeat ${ }^{*} p=0.033 ; G A D 2 /$ defeat vs Pet1/defeat ${ }^{* * *} p<0.001 ; G A D 2 /$ defeat vs GAD2/undefeated ${ }^{\S} p<0.001 ; n=3-7$ per group). $L$, Confocal image depicting the distribution of vmPFC axon terminals in the DRN after anterograde tracing of excitatory vmPFC neurons using AAV-mediated expression of ChR2-YFP driven by the CaMKIlla promoter. Note the dense clustering of tagged terminals in the lateral portion of DRN corresponding to the areas rich in CFos expressing GABAergic neurons after social defeat (dashed circles).

activated cells identified in this study overlap with the cellular population identified in our previous study (Berton et al., 2007). The relatively restricted localization of $c$ Fos to the lateral areas of the DRN also suggests that it may be driven by descending inputs that are topographically distributed in this area. Viral tracing studies from the Allen Brain Atlas (Sunkin et al., 2013), corroborated by our own anterograde tracing data (Fig. $1 L$ ), indicate that one such afferent input originates from the ventromedial prefrontal cortex (vmPFC), an area thought to be important for social cognition (Roy et al., 2012). Indeed, we observed a striking similarity between the distribution of anterogradely traced vmPFC axons and defeat-induced $c F o s$ in the DRN (Fig. $1 C, F, I, L)$.

Quantification of $c F$ os colocalization with native GAD1-GFP (Fig. 1C), GAD2-tdTomato (Fig. 1F), or Pet1-tdTomato (Fig. 1I) fluorescence revealed significantly greater $c F o s$ induction in GAD2-labeled compared with GAD1- and Pet1-labeled cells (two-way ANOVA, genotype $\times$ condition, $F_{(2,24)}=12.79, p=$ 0.004; Fig. $1 K)$. These results reinforce the notion that social defeat induces activation of DRN neurons and further demonstrates that GABAergic neurons, more specifically $G A D 2^{+}$neu- rons, are a predominant social-stress-activated cell type in the DRN.

Sensitization of DRN GABA neurons in SUS mice after social defeat coincides with increased 5-HT inhibition

Given the significant increase in GAD2-specific GABAergic cFos induction after social defeat, we next examined functional adaptations after defeat in this cell type by conducting whole-cell patch-clamp recordings in midbrain slices from control and defeated mice. The use of the GAD2-tdTomato mouse line allowed us to unequivocally identify GABA cells for recordings. After defeating GAD2-tdTomato mice, we determined their social interaction, distinguishing between RES (high social interaction) and SUS (low social interaction) subpopulations, and prepared brain slices for whole-cell patch-clamp electrophysiology. We focused recordings in the ventrolateral area (i.e., lateral wings; Fig. $2 A$ ) of the DRN, which shows the highest-density GABA cell distribution and $c F o s$ induction after social defeat (Fig. $1 D-F$ ) and is also a region that receives strong excitatory input from the vmPFC (Figs. 1L, 2A, inset; Jankowski and Sesack, 2004). 


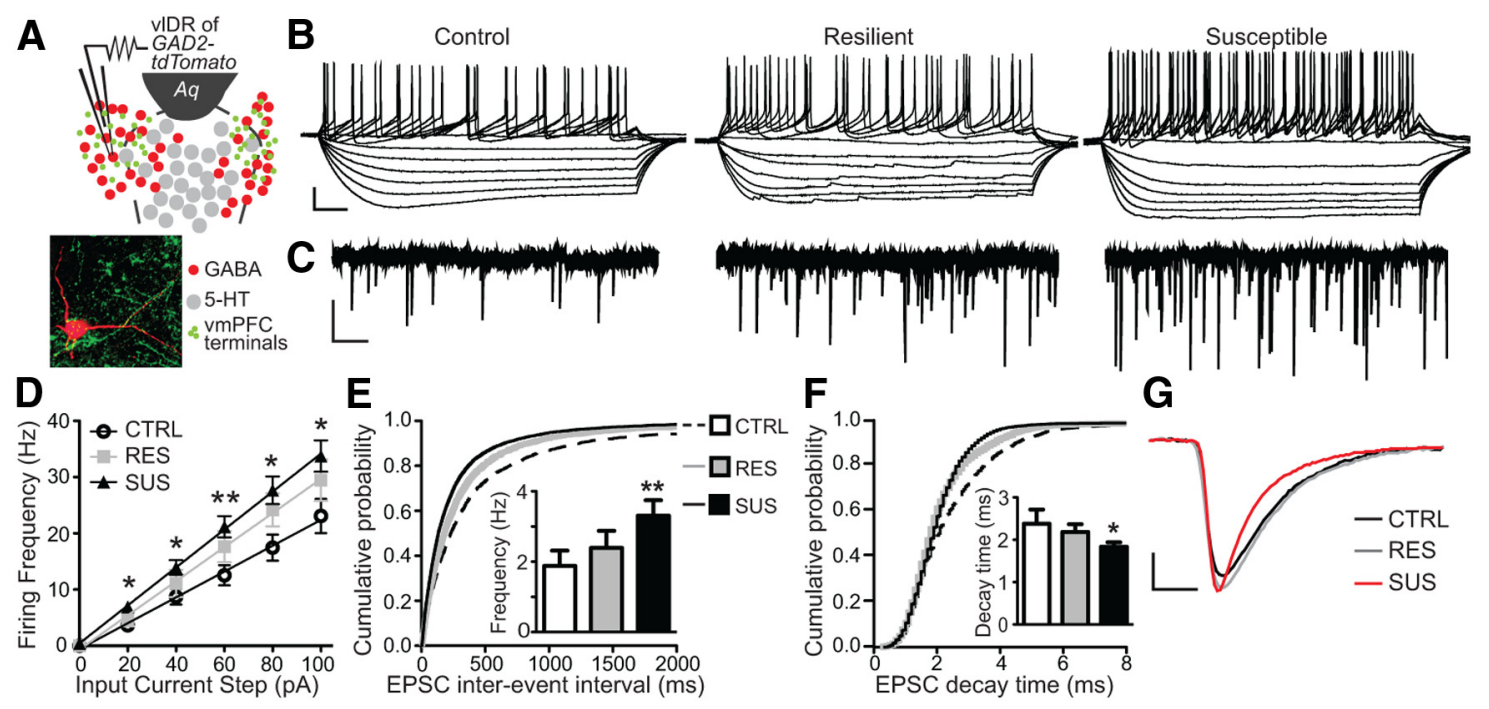

Figure 2. Social defeat sensitized excitatory input and excitability of vmPFC-innervated DRN GABAergic neurons in SUS mice but not in RES mice. $A$, Schematic of DRN topography in recorded slices from GAD2-tdTomato mice. vIDR, ventrolateral DRN; $A q$, aqueduct. Recorded neurons were purposely selected in ventrolateral subregions of the DRN that are rich in afferents from the vmPFC. Inset depicts a high-magnification confocal image of a biocytin-filled recorded GAD2-tdTomato neuron (red) in close contact with axon terminals from vmPF( neurons (green) anterogradely traced using AAV-CaMKIla-ChR2-YFP. B, Raw data traces of membrane potential changes recorded from DRN GABA neurons in response to hyperpolarizing and depolarizing injection of current in control, RES, and SUS mice. Scale bar, $20 \mathrm{mV}, 50 \mathrm{~ms}$. C, Representative voltage-clamp traces of mEPSC synaptic activity in DRN GABA neurons from control, RES, and SUS mice. Scale bar, $20 \mathrm{pA}, 500 \mathrm{~ms}$. D, Frequency-intensity plots showed increased excitability of DRN GABA neurons in SUS mice [repeated-measures ANOVA, Fisher's post hoc; SUS vs CTRL, $20 \mathrm{pA}{ }^{*} p=0.030,40 \mathrm{pA}{ }^{*} p=0.034,60 \mathrm{pA}$ ${ }^{* *} p=0.008,80 \mathrm{pA}^{*} p=0.012,100 \mathrm{pA}^{*} p=0.025 ; N(n)=7(29)$ for control, $4(20)$ for RES, 10 (37) for SUS]. $\boldsymbol{E}$, Cumulative probability plot shows a shift to shorter interstimulus intervals of mEPSC synaptic activity in DRN GABA neurons of SUS mice versus control or RES mice (Kolmogorov-Smirnov test, $Z=7.1402, p<0.001$ ). Inset displays summary histogram showing significantly higher average mEPSC frequency in SUS mice (one-way ANOVA, Fisher's post hoc; SUS vs (TRL ${ }^{* *} p=0.006$ ). $\boldsymbol{F}$, Cumulative probability plot of mEPSC decay time shows the shift to faster decay times in DRN GABA neurons of SUS mice (Kolmogorov-Smirnov test, $Z=6.4021, p<0.001$ ). Inset shows summary histogram depicting the significantly lower average mEPSC decay times in SUS mice versus control and RES mice (one-way ANOVA, Fisher's post hoc; SUS vs CTRL * $p=0.014$ ). G, Enlarged depiction of averaged individual EPSC synaptic events in GABA neurons for each group. Scale bar, 4 pA, 2 ms.

The intrinsic properties of DRN GAD2 ${ }^{+}$GABA neurons were distinct from those of identified 5-HT cells (Crawford et al., 2010): they displayed a higher membrane resistance $\{G A D 2=$ $944 \pm 75 \mathrm{M} \Omega$ vs Pet $1=583 \pm 39 \mathrm{M} \Omega ; G A D 2$ number of mice (number of cells) $=7(29)$, Pet1 $=3(16)]$ and had shorterduration action potentials $(G A D 2=1.68 \pm 0.11 \mathrm{~ms}$ vs Pet $1=$ $2.4 \pm 0.1)$. The GABA characteristics were similar to those of previously reported recordings from GABA neurons (Brown et al., 2008; Wierenga et al., 2010; McKenna et al., 2013). Furthermore, in contrast to 5-HT cells, which are silent in brain slice preparations, $\sim 40 \%$ of recorded GABA neurons displayed spontaneous firing activity at an average rate of $6.6 \pm 1.1 \mathrm{~Hz}$. We next determined the membrane responses of these cells to $20 \mathrm{pA}$ steps of depolarizing injected current (Fig. $2 B$ ) and found that DRN GABA neurons in SUS mice had a significant increase in the number of action potentials elicited versus controls. In contrast, cell excitability of GABA neurons in RES mice did not significantly differ from undefeated mice [repeated-measures ANOVA, defeat $\times$ input current, $F_{(2,460)}=2.40, p=0.010$; number of mice (number of neurons) $\{N(n)\}=7(29)$ for control, $4(20)$ for RES, 10(37) for SUS; Fig. $2 B, D]$ ). We then investigated whether excitatory synaptic inputs to these neurons had been changed by social defeat using voltage-clamp techniques (Crawford et al., 2011). Recording of spontaneous glutamatergic EPSC activity from GAD2-tdTomato neurons in each behavioral group revealed a significant increase in the overall EPSC frequency in DRN GABA neurons of SUS mice compared with controls, but not in RES mice (one-way ANOVA, $F_{(2,78)}=4.08, p=0.021$; Fig. $2 C, E$, inset histogram). This was confirmed by a significant shift in the cumulative probability plot of interstimulus intervals (KolmogorovSmirnov test, $Z=7.14, p<0.001$; Fig. $2 E$ ). In the presence of TTX, mEPSC frequency was not altered, implying that the re- corded excitatory events were not due to local, actively firing neurons [data not shown; $N(n)=3(13)$ ]. Analysis of synaptic current kinetics for individual events revealed a significant decrease in event decay time in SUS mice, leading to the possibility of altered AMPA receptor conformation or phosphorylation (one-way ANOVA, $F_{(2,78)}=3.13, p=0.049$; Fig. $2 F, G$, inset histograms). This was also confirmed by a significant shift in the cumulative probability plot of decay times (Kolmogorov-Smirnov test, $Z=6.40, p<0.001$; Fig. $2 F$ ).

To determine whether social defeat also induced adaptations in 5-HT neurons, we next conducted recordings in slices from defeated Pet1-tdTomato mice, focusing on neurons in the dorsomedial and ventromedial DRN (Fig. 3C). Similar to DRN GABA neurons, we found that social defeat altered the membrane properties and synaptic activity of genetically identified 5-HT neurons, with differences between the SUS and RES subgroups. In contrast to the sensitization observed in GABA neurons, we found that 5-HT neurons of SUS mice had reduced intrinsic excitability [repeated-measures ANOVA, defeat $X$ input current, $F_{(12,228)}=2.79, p=0.001 ; N(n)=3(15)$ for control, 3(16) for RES, 3(21) for SUS; Fig. $3 A, D$ ]. In the 5-HT neurons, IPSC activity was measured as described previously (Crawford et al., 2013). In SUS mice, mIPSC frequency was increased compared with controls (one-way ANOVA, $F_{(2,28)}=3.52, p=0.043$; Fig. $3 B$ and $E$, inset). The change in frequency was confirmed by a significant shift in the cumulative probability plot of inter-IPSC intervals (Kolmogorov-Smirnov, $Z=8.65, p<0.001$; Fig. $3 E$ ). In addition, there was a trend toward a significant increase in EPSC frequency in Pet1-tdTomato neurons of RES mice compared with controls (one-way ANOVA, $F_{(2,28)}=2.82, p=0.076$; data not shown). These results support the hypothesis that expression of social avoidance in stress SUS mice was associated with sensitized 
A

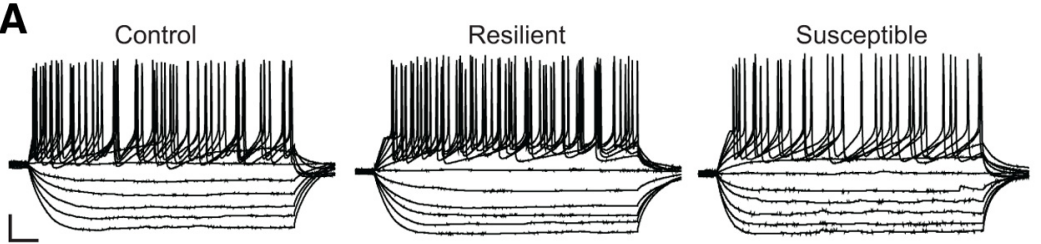

B

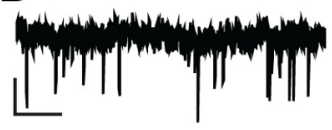

C

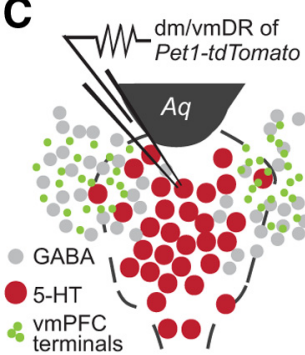

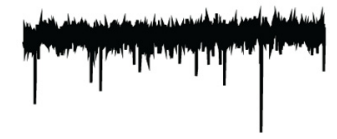

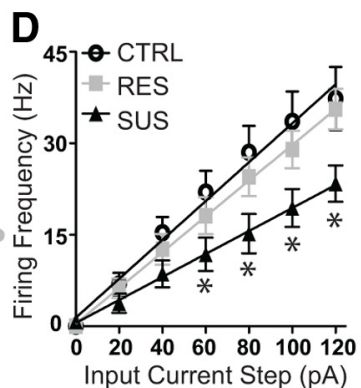

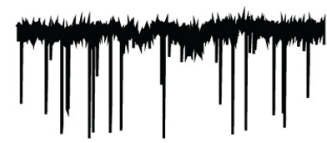
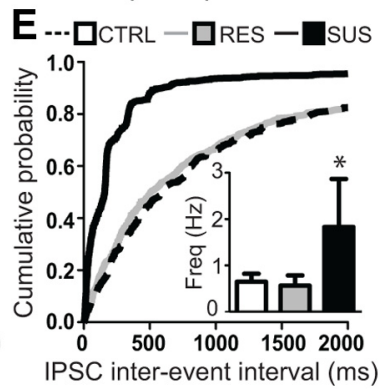

Figure 3. Social defeat decreased excitability and enhanced inhibitory input of DRN 5-HT neurons of SUS mice. A, Raw data traces of membrane potential changes recorded from DRN 5-HT neurons in response to hyperpolarizing and depolarizing current injection in control, RES, and SUS mice. Scale bar, $20 \mathrm{mV}, 50 \mathrm{~ms}$. $\boldsymbol{B}$, Representative traces of mIPSC activity in DRN 5-HT neurons from control, RES, and SUS mice. Scale bar, 20 pA, 2 s. C, Schematic of DRN topography in recorded slices from Pet1-tdTomato mice. $\mathrm{dm} / \mathrm{vmDR}$, dorsomedial/ventromedial DRN; $A q$, aqueduct. $\boldsymbol{D}$, Frequency-intensity plots show decreased excitability of DRN 5-HT neurons in SUS mice [repeated-measures ANOVA, Fisher's posthoc; SUS vs CTRL, 60 pA * $p=0.043,80 \mathrm{pA}^{*} p=0.024,100 \mathrm{pA}^{*} p=$ $0.023,120 \mathrm{pA}^{*} p=0.033 ; N(n)=3(15)$ for control, 3(16) for RES, 3(21) for SUS]. $\boldsymbol{E}$, Cumulative probability plots show the shift to shorter interstimulus intervals of mIPSC activity in DRN 5-HT neurons of SUS mice versus control or RES mice (Kolmogorov-Smirnov test, $Z=8.652, p<0.001$ ). Inset displays summary histogram depicting the significantly higher average mIPSC frequency in SUS mice (one-way ANOVA, Fisher's post hoc; SUS vs CTRL * $p=0.035$ ).

descending excitatory input onto DRN GABAergic neurons, which in turn carried into an enhanced inhibition of neighboring 5-HT neurons.

\section{Optogenetic silencing of ventrolateral DRN GABA neurons disinhibits midline 5-HT neurons}

To determine the causal involvement of DRN GABA neuron sensitization in the expression of behaviors associated with the SUS phenotype, we adopted an optogenetic silencing approach that we applied in slices and in freely moving animals. To achieve GABA neuron silencing, we expressed a GFPtagged version of the inhibitory optogenetic effector Archaerhodopsin (Arch-GFP; Chow et al., 2010). We infused a Cre-recombinase-inducible AAV vector into the DRN of GAD2Cre mice to selectively target Arch-GFP to GABA neurons. In mice perfused 6 weeks after injection, counting of $\mathrm{GFP}^{+}$cells along the entire rostrocaudal extent of the DRN showed that $\sim 21 \%$ of $\mathrm{GAD}^{+}{ }^{+}$DRN neurons $(248.5 \pm 8.8$ per field of view) were transduced and expressed Arch-GFP (51.75 $\pm 8.7 ; n=4)$. No Arch-GFP ${ }^{+} / G A D 2^{-}$cells were detected, confirming the selectivity of viral targeting (Student's $t$ test, $t_{(6)}=6.37, p<0.001$; data not shown). Numerous GAD2 ${ }^{+} /$Arch-GFP ${ }^{+}$neurons were found in ventrolateral portions of the DRN (Fig. 4Ai). These cells were clearly distinct from, but in close proximity to, 5-HT neurons identified using immunolabeling of tryptophan hydroxylase (TPH; Fig. 5Aii-Aiv). To validate Arch-mediated silencing of GABA neurons, we conducted whole-cell recordings in DRN slices 6 weeks after viral stereotaxic injection. When recording from visually identified GABA neurons that were spontaneously firing (Fig. 4D), application of $543 \mathrm{~nm}$ light at an irradiance of ap- proximately $10.01 \mathrm{~mW} \mathrm{~mm}^{-2}$ resulted in time-locked silencing (Fig. 4B). Firing was completely abolished when the laser was on and returned upon cessation of illumination, with activity often rebounding at an increased firing rate [repeated-measures ANOVA, $F_{(2,53)}=3.53, p<0.001 ; N(n)=$ 3(18); Fig. 4E].

We then investigated whether identified $G A D 2^{+}$cells in the ventrolateral DRN form local connections with nearby 5-HT neurons present on the same slice. To our knowledge, despite multiple references in the literature indicating that DRN GABA neurons synapse with 5-HT neurons (Celada et al., 2001; Varga et al., 2001; Hou et al., 2012), there is currently no direct evidence demonstrating monosynaptic inhibition of DRN 5-HT cells by neighboring GABA neurons. To investigate this, we applied the same silencing protocol as above, but recorded from $t d$ Tomato $^{-} / \mathrm{GFP}^{-}$neurons located in the 5-HT-rich midline area of the DRN (Fig. 4D). For this experiment, 5-HT cell type was predicted primarily based on identification of firing patterns typical of 5-HT neurons (Crawford et al., 2010). However, because this electrophysiological criterion is not entirely reliable, neurochemical identity was also confirmed a posteriori using biocytin filling and $\mathrm{TPH}$ immunolabeling (Fig. 4Av). Laser illumination resulted in a significant decrease in IPSC frequency in $17 \%$ of recorded 5 -HT cells and, as noted previously for GABA neurons, rebounded to levels greater than baseline upon cessation of laser illumination [repeated-measures ANOVA, $F_{(2,14)}=7.33, p<0.001 ; N(n)=2(5)$; Fig. $\left.4 C, F\right]$. Those 5-HT neurons responsive to the laser inhibition of GABA synaptic activity were located in the dorsomedial DRN. These results provide definitive evidence of DRN GABA neurons that locally synapse on and inhibit 5-HT neurons.

\section{Silencing DRN GABA neurons interferes with the} development of but not the expression of social aversion DRN circuits might contribute to the development of social avoidance in SUS mice by affecting a number of different processes. For example, DRN output could mediate negative perceptive biases in which detection and processing of threatening socioemotional information (e.g., body postures, auditory and olfactory cues) become sensitized after defeat (Todorov, 2008; Passamonti et al., 2012; Roy et al., 2012). Alternatively, these circuits could also affect the threshold for the execution of approach/avoidance responses through effects on decisions to engage in actions (i.e., execution of approach; Miller and Cohen, 2001; Rogers, 2011; Volman et al., 2011). To dissociate these two potentially distinct roles, we manipulated DRN GABA neurons optogenetically, either during the phase corresponding to the associative encoding of social threat (physical defeat/sensory contact; Fig. 6 A, top row) or execution of a previously acquired social avoidance response (social interaction testing; Fig. $6 A$, bottom row).

We hypothesized that a critical encoding period may be when mice are maintained in sensory contact with their aggressor after physical aggression. To investigate this, we compared avoidance 

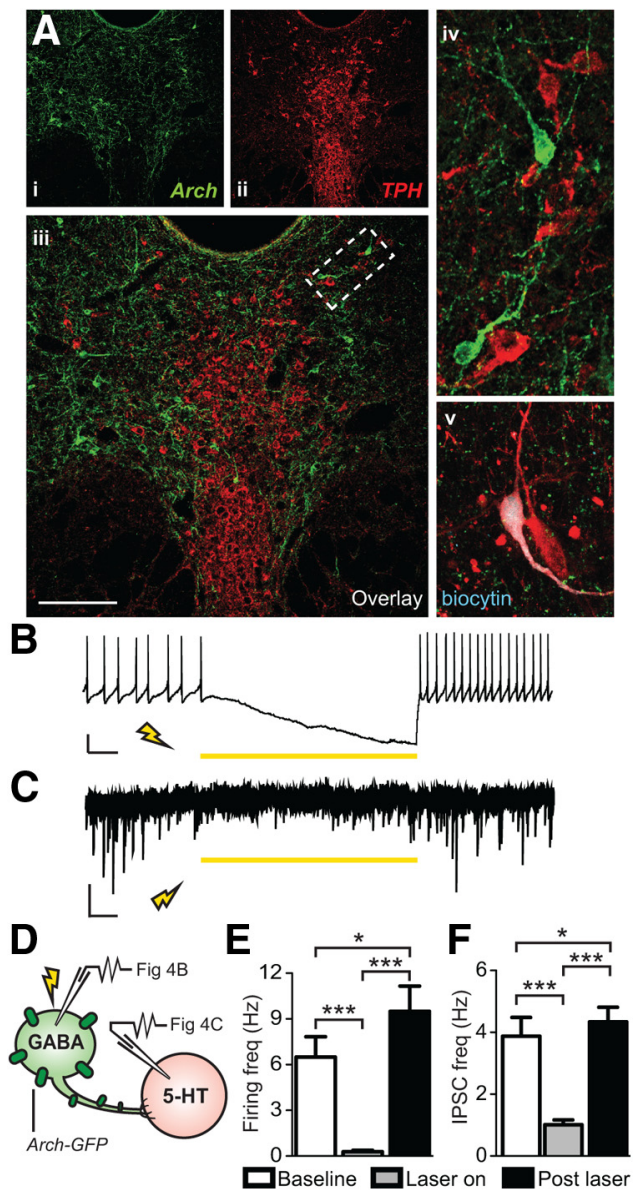

Figure 4. Archaerhodopsin-mediated photoinhibition of DRN GABAergic neurons silenced their spontaneous firing and decreased IPSC activity of neighboring 5-HT neurons. Ai-Aiv, Confocal image of Arch-GFP-expressing GABAergic neurons (green) and TPH labeled 5-HT neurons (red) in the DRN. Scale bar, $50 \mu \mathrm{m}$. Av, Example of a 5-HT neuron recorded in the DRN that was filled with biocytin and its neurochemical identity was confirmed a posteriori using $T P H$ immunostaining. $B$, Current-clamp trace of a spontaneously firing, Arch-expressing $\mathrm{GAD2}^{+}{ }^{+} \mathrm{GABA}$ neuron. Exposure to $318 \mathrm{~mW} \mathrm{~mm}^{-2}$ of $593 \mathrm{~nm}$ light inhibited the tonic firing. Scale bar, $20 \mathrm{mV}, 1 \mathrm{~s}$. C, Voltage-clamp recording from a later identified 5-HT neuron. Illumination of the DRN with $318 \mathrm{~mW} \mathrm{~mm}^{-2}$ of $593 \mathrm{~nm}$ light resulted in a reduction of IPSC frequency that returned upon cessation of laser stimulation. Scale bar, 10 pA, 1 S. D, Schematic of recording experiments. Whole-cell patch-clamp was performed on either GABA or 5-HT neurons while Arch-expressing GABA neurons were photoinhibited via laser stimulation. $\boldsymbol{E}$, Summary histogram showing that laser illumination resulted in complete silencing of spontaneous firing of $\mathrm{GAD2}^{+} \mathrm{GABA}$ neurons $[N(n)=3(18)]$ that was restored upon laser cessation (repeated-measures ANOVA, Fisher's post hoc; baseline vs laser, ${ }^{* * *} p<0.001$; laser vs post-stim ${ }^{* * *} p<0.001$; baseline vs post-stim $\left.{ }^{*} p=0.030\right)$. $\boldsymbol{F}$, Summary histogram showing that laser stimulation reduced IPSC frequency in 5 -HT neurons $[N(n)=2(5)]$ that was restored after laser cessation (repeated-measures ANOVA, Fisher's posthoc; baseline vslaser ${ }^{* *} p<0.001$; laservs post-stim ${ }^{* * *} p<0.001$; baseline vs post-stim $\left.{ }^{*} p=0.047\right)$.

behavior of mice that underwent $10 \mathrm{~d}$ of standard defeat $(5 \mathrm{~min}$ of physical contact +24 h of sensory contact with aggressor through a Plexiglas partition) to mice that experienced a physical defeat experience without subsequent sensory contact with the aggressor ( 5 min of physical contact +24 h home cage; Fig. $5 A$ ). This comparison revealed that a sensory contact period is required for the subsequent expression of the avoidance response (one-way ANOVA, $F_{(3,37)}=8.34, p=0.002 ; n=9-12$ per group; Fig. $5 B$ ). We then determined the minimal duration of sensory contact necessary for the expression of social avoidance. Comparing various durations, we found that $20 \mathrm{~min}$ of postdefeat sensory exposure to the aggressor was sufficient to allow full expression of avoidance behavior (Fig. 5B). These results reveal the existence of a critical period after physical defeat during which key sensory and associative processes establish the intensity and stability of subsequent avoidance behaviors.

We next investigated the role of DRN GABA neurons by silencing them either during the daily sensory contact period (encoding) or during the 5 min interaction test when mice were evaluated for approach-avoidance decisions in the presence of an unfamiliar social target (execution). Cohorts of mice injected with AAV vectors coding for Cre-dependent expression of ArchGFP or tdTomato in DRN GABA neurons, as described above, were implanted chronically with a fiber optic ferrule used to subsequently connect to an external light source. Mice were exposed to $5 \mathrm{~min}$ of physical contact with aggressors, followed by $20 \mathrm{~min}$ of sensory contact, during which time they were connected to the light source. For the entire duration of the sensory contact period, DRN GABA neurons were silenced ( $543 \mathrm{~nm}, 10 \mathrm{~mW}$ ) and then mice were returned to their home cages overnight (Fig. $6 A$, top row). A cohort of mice expressing tdTomato in GABA neurons was exposed to the identical defeat and laser illumination protocol. Groups of undefeated control mice, injected with Arch-GFP or $t$ TTomato and exposed to identical procedures apart from the 5 min of physical contact, were also included as controls in subsequent tests to evaluate possible effects of GABA silencing independently of defeat experience. Like the social defeat procedure described above, this procedure was conducted for $10 \mathrm{~d}$.

When subsequently tested for social interaction, defeated mice receiving the $t d$ Tomato virus showed typical social avoidance responses, indicating that the laser illumination procedure per se does not influence development of social avoidance. In contrast, defeated mice exposed to DRN GABA silencing during sensory contact exhibited similar levels of social interaction as undefeated mice (twoway ANOVA, virus $\times$ defeat, $F_{(7,38)}=8.07, p<0.001 ; n=6-8$ per group; Fig. $6 B$, left). The effects of DRN GABA silencing were specific to the regulation of social experience because neither virus nor laser condition had significant effects on total movement (data not shown) or the time spent in the interaction zone in the absence of a social target (Fig. 6B, right).

Finally, having shown that DRN GABA neurons contribute to the encoding of avoidance behavior, we investigated whether they also influence processes related to the execution of social avoidance responses (i.e., decision or ability to avoid social interaction). We tested this by silencing DRN GABA neurons after defeat-induced social avoidance had already been established (Fig. 6A, bottom). In contrast to our previous observation, we found that the time spent in the social interaction zone after defeat remained low in both $A r c h$ and $t d$ Tomato groups (two-way ANOVA, main effect of defeat, $F_{(3,13)}=24.39, p<0.001 ; n=5-6$ per group; Fig. $6 C$ ). These results indicate that the activity of DRN GABA neurons is critical during the appraisal or neural encoding of social threat, but is dispensable during the execution of previously established social avoidance responses.

DRN GABA neurons do not mediate increased anxiety-related behaviors after social defeat

Studies have reported a high rate of comorbidity between depression and anxiety disorders (Pollack, 2005). Because GABA activity within the DRN has been implicated in anxiety-related behaviors (Ettenberg et al., 2011; Crawford et al., 2013), we also investigated whether GABA inhibition during the sensory contact phase of social defeat blocked the anxiogeneic effect of defeat, another known consequence of the social defeat paradigm (Krishnan et al., 2007). We investigated this using the OFT and EPM tests. In agreement with previous studies, social defeat had 
A

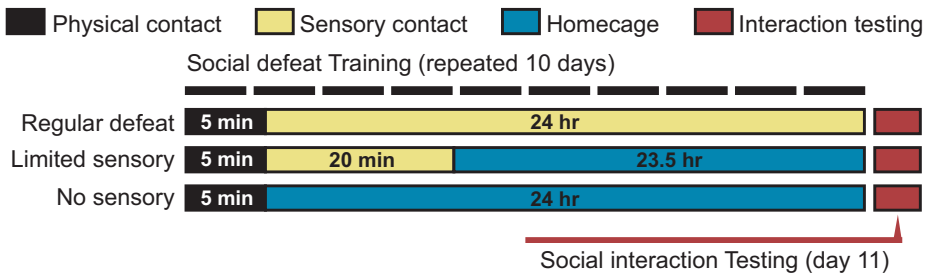

B

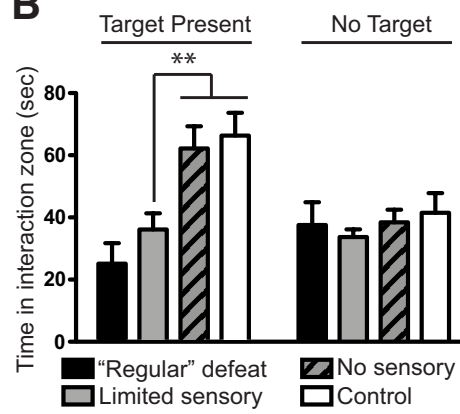

Figure 5. Sensory contact was necessary for encoding of avoidance behavior. $A$, Experimental conditions used to evaluate the contribution of sensory contact to acquisition of social avoidance behavior. During social defeat, all groups received 5 min of physical contact with an aggressor, followed by variable durations of sensory exposure through a Plexiglas divider. The "Regular Defeat" group remained in sensory contact overnight with the aggressor, whereas the "Limited Sensory" group was maintained in sensory contact only for 20 min before being transferred into single housing overnight. In the "No Sensory" group, mice were individually housed immediately after physical contact. These conditions were repeated for $10 \mathrm{~d}$, with exposure to a novel aggressor each day. Social avoidance was tested on day $11,24 \mathrm{~h}$ after last physical defeat exposure. $\boldsymbol{B}$, Compared with undefeated controls, mice from the Limited Sensory group displayed a level of social avoidance comparable to the Regular Defeat group. In contrast, mice from the No Sensory group did not display a significant decrease in interaction compared with undefeated controls (one-way ANOVA, Fisher's post hoc; limited vs no sensory ${ }^{* *} p=0.005$; limited vs control ${ }^{* *} p=0.005 ; n=8-13$ per group). Without a novel target present, durations in the interaction zone did not differ between groups.

A Photoinhibition during Training

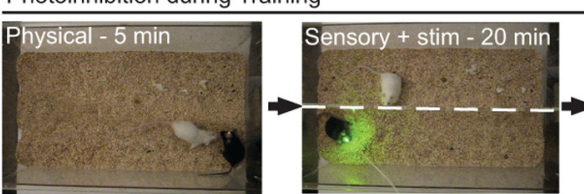

Photoinhibition during Testing

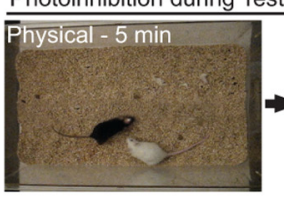

B

GAD2-Cre/Arch

Photoinhibition during Training

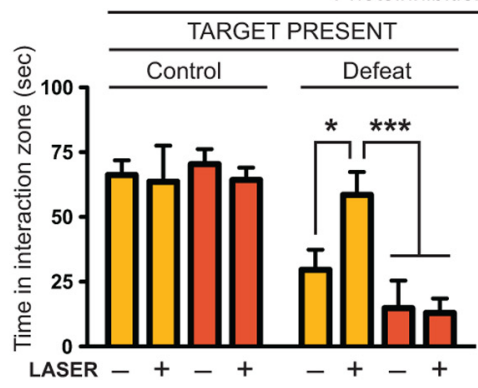

$\mathrm{x} 10$

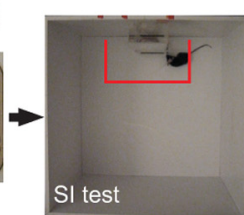

$\times 10$
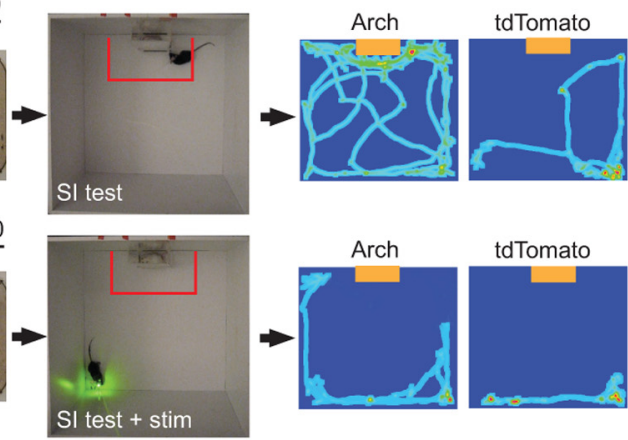

C

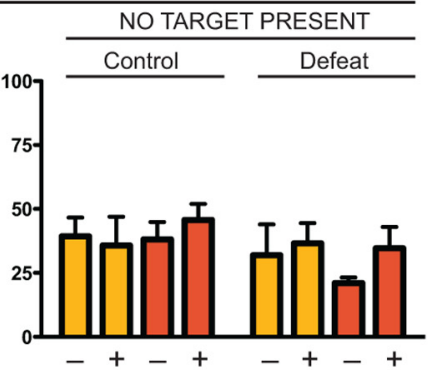

Figure 6. Photoinhibition of DRN GABA neurons prevented the acquisition but not the expression of social avoidance behavior. Two cohorts of $G A D 2$ - $C r e$ mice were injected in the DRN with Cre-dependent $A A V$ vectors, driving expression of Arch-GFP or a sham $t d T$ Tomato protein selectively in DRN GABA neurons. The first cohort ( $\boldsymbol{A}$, top row: photoinhibition during training) received daily photoinhibition during 20 min of sensory contact after physical aggression. The second cohort ( $\boldsymbol{A}$, bottom row: photoinhibition during testing) received photoinhibition only during the social interaction task. Heat maps depict representative behavioral effects of DRN GABA photoinhibition. Corresponding group averages are shown for the time spent in the interaction zone in Control and Defeated mice receiving photoinhibition during the sensory contact period $(\boldsymbol{B})$ or during the social interaction task (C). Light application during daily sensory contact period abrogated social avoidance in Arch-GFP-targeted but not in tdTomato-targeted mice (two-way ANOVA, Fisher's post hoc; defeated Arch/stim vs defeated Arch/no stim ${ }^{*} p=0.011$; defeated Arch/stim vs defeated tdTomato ${ }^{* *} p<0.001 ; n=6-8$ per group). In contrast, no significant effects were observed when light was applied during the social interaction task (two-way ANOVA, Fisher's post hoc; Arch CTRL vs DEF ***p $<0.001$ ). Note that GABA photoinhibition had no effect on the behaviors of mice tested in the absence of a social target and that laser illumination per se was devoid of effect in mice expressing tdTomato.

an anxiogenic effect in both tests because defeated mice spent less time in the center of the OFT arena compared with undefeated controls (two-way ANOVA, main effect of defeat, $F_{(1,46)}=21.60$, $p<0.001 ; n=6-8$ per group; Table 1$)$. However, there was no distinction between mice receiving DRN GABA neuron inhibition during social defeat and unstimulated mice. A similar lack of effect of optogenetic stimulation was also observed in the EPM test, where both stimulated and unstimulated mice displayed similar levels anxiety-like behaviors (i.e., decreased time spent in open arms, increased entries into closed arms; Table 2). This suggests that DRN GABA neurons play a specific role in social avoidance, but are dispensable for the encoding of social defeatmediated anxiety-related behaviors.

\section{Discussion}

Our primary finding showed that social defeat sensitized DRN GABA neurons and increased GABA-mediated inhibition of 
Table 1. DRN GABA inhibition effects on anxiety-related behaviors: OFT

\begin{tabular}{llllll}
\hline & \multicolumn{3}{l}{ Time in center of arena $(\mathrm{s})$} & & \\
\cline { 2 - 3 } \cline { 5 - 6 } & GAD2-Cre/Arch & & & \\
\cline { 2 - 5 } Stim $( \pm)$ & + & - & + & - \\
\hline Defeated & $28.94 \pm 7.19^{* * *}$ & $28.89 \pm 6.61^{* * *}$ & $25.56 \pm 7.38^{* * *}$ & $25.54 \pm 9.34^{* * *}$ \\
Control & $56.09 \pm 10.47$ & $46.86 \pm 8.59$ & & $50.50 \pm 4.13$ & $42.81 \pm 8.79$ \\
\hline
\end{tabular}

Data are expressed as mean time in the center of arena \pm SEM.

***Significant difference in defeated mice from undefeated controls of the same virus (GAD2-Cre/Arch or GAD2-Cre) tdTomato) and stimulation ( + or - ) condition ( $p<0.01$, two-way ANOVA, Fisher's post hoc, control vs defeated).

Table 2. DRN GABA inhibition effects on anxiety-related behaviors: EPM

\begin{tabular}{|c|c|c|c|c|}
\hline \multirow[b]{3}{*}{ Stim (士) } & \multicolumn{4}{|c|}{ Defeated mice } \\
\hline & \multicolumn{2}{|c|}{ GAD2-Cre/Arch } & \multicolumn{2}{|c|}{ GAD2-Cre/tdTomato } \\
\hline & + & - & + & - \\
\hline Time in open arms (s) & $6.30 \pm 2.27$ & $5.66 \pm 3.77$ & $4.69 \pm 1.48$ & $4.77 \pm 2.94$ \\
\hline Time in closed arms (s) & $267 \pm 6.5$ & $254.50 \pm 7.76$ & $273.42 \pm 6.86$ & $271.65 \pm 8.00$ \\
\hline Open arm entries (no.) & $6 \pm 1$ & $4 \pm 1$ & $5 \pm 2$ & $3 \pm 1$ \\
\hline Closed arm entries (no.) & $15 \pm 2$ & $11 \pm 2$ & $13 \pm 4$ & $11 \pm 3$ \\
\hline
\end{tabular}

Data are expressed as mean time spent in arms or the number of arm entries \pm SEM. There were no significant differences between conditions.

5-HT neurons in SUS mice. In contrast, RES mice escaped this effect and displayed unaltered GABA and 5-HT neuronal excitability. Furthermore, GABA silencing disinhibited 5-HT cells and promoted a RES phenotype in mice exposed to social defeat. Therefore, we have established a role for DRN GABA neurons in the neural encoding of social threats. By identifying cellular mechanisms underlying stable social approach/avoidance decision biases in mice exposed to social defeat, our results contribute to a better neurobiological understanding of the neural circuitry underlying socioemotional deficits increasingly conceived as part of the cognitive core of mood and anxiety disorders (Beck, 2008; Cusi et al., 2012; Roiser et al., 2012).

\section{GABAergic neurons provide inhibitory control of 5-HT neurons in the DRN microcircuit}

Aside from 5-HT neurons, the DRN contains a large proportion (estimated 50-75\%) of non-5-HT cells comprised primarily of GABA- and glutamate-producing neurons (Fu et al., 2010; Bang and Commons, 2012). Pharmacological and neuroanatomical evidence supports the notion that, in concert with 5-HT autoreceptor-mediated mechanisms, GABA neurons are key to the inhibitory control of 5-HT systems (Liu et al., 2000; Varga et al., 2001). Based on converging data from previous in vivo recording and tracing studies, GABA neurons located within the DRN may serve as local inhibitory relays for several major descending excitatory inputs converging onto the DRN, including those originating from the vmPFC and lateral habenula (Celada et al., 2001; Varga et al., 2001; Varga et al., 2003). Using Archaerhodopsinmediated silencing, we have shown here that DRN GAD2 ${ }^{+}$ GABA neurons connect monosynaptically to local 5-HT neurons, providing a source of postsynaptic inhibitory currents to $\sim 20 \%$ of 5 -HT cells probed in the medial DRN. This proportion, however, is almost certainly an underestimate considering that the brain slice preparation used for electrophysiology likely disrupted axonal connections for at least some GABA neurons. Our results provide evidence confirming that this hypothetical organization of DRN microcircuits exists and confirms the role of GABA neurons in affective regulation.

\section{Defeat drives adaptations in DRN GABA and 5-HT neurons that discriminate RES from SUS mice}

Our previous study demonstrated that DRN 5-HT neurons identified using postrecording immunolabeling underwent social defeat-induced physiological adaptations (Espallergues et al., 2012); however, it did not reveal clear distinctions between RES and SUS subpopulations. Here, using a genetic labeling method that facilitated cell typing, we observed differences between behavioral subgroups and found that DRN neurons in SUS mice undergo clear adaptations, whereas the properties of the neurons in RES mice more closely resemble those of undefeated controls. In SUS mice, the DRN 5-HT neuronal population had decreased excitability and increased inhibitory input. The source of this inhibitory synaptic activity is likely from local DRN GABA neurons, which we found were hyperexcitable and also driven by increased excitatory input in SUS mice. These adaptations in both GABA and 5-HT neurons, when coupled together, suggest an overall decrease in 5-HT excitability in SUS mice, which is consistent with literature describing the role of 5-HT in socioaffective regulation (Raleigh et al., 1991; Liu et al., 2010; Bilderbeck et al., 2011; Passamonti et al., 2012).

Alhough we did not formally demonstrate the source of the increased excitatory input on DRN GABAergic neurons, our tracing results indicate that the likely driving brain region is the ventral mPFC. Indeed, the distribution of CaMKIIa-driven YFP labeling of vmPFC axonal terminals in the DRN shows a striking overlap with the distribution of defeat-activated GABA neurons. Furthermore, ultrastructural studies of vmPFC axons in the DRN have shown that they preferentially target GABA neurons over 5 -HT neurons (Jankowski and Sesack, 2004). The vmPFC is thought to play a role in determining social valence (Roy et al., 2012), so it is plausible that vmPFC afferents to the DRN modulate 5-HT tone via GABAergic neurons, affecting socioaffective judgment. Our results are consistent with the antidepressant-like effects of vmPFC DBS in rats, which increases 5-HT output in certain forebrain projection areas (Hamani et al., 2010; Hamani et al., 2012). However, recent studies further emphasized the complex role of vmPFC-DRN pathways in depression-related behaviors by reporting similar antidepressant-like effects in the forced swim test in rats after direct optogenetic activation of glutamatergic vmPFC terminals in the DRN or direct stimulation of a mixed GABA/5-HT DRN neuronal population (Warden et al., 2012). Based on this, it is likely that partially distinct vmPFCDRN subcircuits modulate escape behaviors to noxious stimuli versus social approach/avoidance and antagonistic behaviors. This view is supported by the fact that a regimen of chronic optogenetic stimulation of Thy ${ }^{+}$layer $\mathrm{V}$ vmPFC neurons in mice that enhanced DRN activity did not influence social avoidance after social defeat, even though this treatment produced long-lasting antidepressant-like effects in the forced swim test (Kumar et al., 2013).

\section{DRN GABAergic neurons mediate associative encoding of social aversion, but are dispensable for the execution of avoidance decisions}

Social defeat is a model of psychosocial stress with predictive validity that has proved useful in examining modes of action of antidepressant therapeutics and the neurobiology of depressionlike behaviors (Kudryavtseva et al., 1991; Krishnan et al., 2008; Golden et al., 2011). An essential aspect of the specific paradigm used in the present study is the application of a daily sensory exposure period, during which time mice were maintained in protected sensory contact with an aggressor after a brief but se- 
vere experience of physical aggression (Berton et al., 2006). After this associative process, an initially positively valenced social stimulus (i.e., an unfamiliar CD1 social target that unconditionally induces approach in control mice) acquires aversive motivational value and triggers social avoidance in the social interaction testing for most defeated mice. This social avoidance response after social defeat observed in SUS mice is generalized and observed independently of the degrees of familiarity, physical appearance, or genetic strain of the social target (Berton et al., 2006). Although the specific sensory modalities of salient social cues involved during the acquisition and expression of avoidance behavior have yet to be determined, our previous studies have shown that the social target actively emits these cues, because the use of an anesthetized target leads to a complete loss of the avoidance response (Krishnan et al., 2007).

In the present study, we identified the critical period during which sensory associations necessary for subsequent expression of social avoidance were established. We showed that these associations occurred during a defined time lapse that spans the first $20 \mathrm{~min}$ after the end of physical contact with the aggressor and demonstrated that this period is both necessary and sufficient for the development of long-lasting social avoidance. Further, we demonstrated using Arch-mediated optogenetic silencing of DRN GAD2 ${ }^{+}$neurons in vivo that activation of DRN GABA neurons was required for acquiring the avoidance response, but were not involved in the expression of a previously acquired avoidance response. The mechanism by which silencing DRN GABA neurons impaired the socioaffective encoding without influencing the execution of social avoidance response remains uncertain. Increases in 5-HT output in the vmPFC after GABA-B receptor activation in the DRN and disinhibition of 5-HT neurons has been shown consistently to promote social approach and offensive behaviors of defeated mice (Takahashi et al., 2010; Takahashi et al., 2012). This is in general agreement with data linking enhancement of forebrain 5-HT output with resilience to social stress and maintenance of dominant social status in various species (Raleigh et al., 1991; Malatynska et al., 2005; Alekseyenko et al., 2010; Penn et al., 2010; Bruchas et al., 2011). Our study identifies the role of GABAergic neurons embedded within DRN microcircuits as that of a pivotal cellular population to regulate mood-affecting 5-HT neurons. By revealing a striking influence of social experiences on the basic neurophysiological characteristics and synaptic properties of these GABA neurons, our results introduce a novel circuitry relevant to affective resilience and treatment of affective disorders.

\section{References}

Alekseyenko OV, Lee C, Kravitz EA (2010) Targeted manipulation of serotonergic neurotransmission affects the escalation of aggression in adult male Drosophila melanogaster. PLoS One 5:e10806. CrossRef Medline

Amat J, Baratta MV, Paul E, Bland ST, Watkins LR, Maier SF (2005) Medial prefrontal cortex determines how stressor controllability affects behavior and dorsal raphe nucleus. Nat Neurosci 8:365-371. CrossRef Medline

Bang SJ, Commons KG (2012) Forebrain GABAergic projections from the dorsal raphe nucleus identified by using GAD67-GFP knock-in mice. J Comp Neurol 520:4157-4167. CrossRef Medline

Bang SJ, Jensen P, Dymecki SM, Commons KG (2012) Projections and interconnections of genetically defined serotonin neurons in mice. Eur J Neurosci 35:85-96. CrossRef Medline

Beck AT (2008) The evolution of the cognitive model of depression and its neurobiological correlates. Am J Psychiatry 165:969-977. CrossRef Medline

Berton O, McClung CA, Dileone RJ, Krishnan V, Renthal W, Russo SJ, Graham D, Tsankova NM, Bolanos CA, Rios M, Monteggia LM, Self DW, Nestler EJ (2006) Essential role of BDNF in the mesolimbic dopamine pathway in social defeat stress. Science 311:864-868. CrossRef Medline
Berton O, Covington HE 3rd, Ebner K, Tsankova NM, Carle TL, Ulery P, Bhonsle A, Barrot M, Krishnan V, Singewald GM, Singewald N, Birnbaum S, Neve RL, Nestler EJ (2007) Induction of deltaFosB in the periaqueductal gray by stress promotes active coping responses. Neuron 55 : 289-300. CrossRef Medline

Bilderbeck AC, McCabe C, Wakeley J, McGlone F, Harris T, Cowen PJ, Rogers RD (2011) Serotonergic activity influences the cognitive appraisal of close intimate relationships in healthy adults. Biol Psychiatry 69:720 -725. CrossRef Medline

Brown RE, McKenna JT, Winston S, Basheer R, Yanagawa Y, Thakkar MM, McCarley RW (2008) Characterization of GABAergic neurons in rapideye-movement sleep controlling regions of the brainstem reticular formation in GAD67-green fluorescent protein knock-in mice. Eur J Neurosci 27:352-363. CrossRef Medline

Bruchas MR, Schindler AG, Shankar H, Messinger DI, Miyatake M, Land BB, Lemos JC, Hagan CE, Neumaier JF, Quintana A, Palmiter RD, Chavkin C (2011) Selective $\mathrm{p} 38 \alpha$ MAPK deletion in serotonergic neurons produces stress resilience in models of depression and addiction. Neuron 71:498511. CrossRef Medline

Calizo LH, Akanwa A, Ma X, Pan YZ, Lemos JC, Craige C, Heemstra LA, Beck SG (2011) Raphe serotonin neurons are not homogenous: electrophysiological, morphological and neurochemical evidence. Neuropharmacology 61:524-543. CrossRef Medline

Canli T, Lesch KP (2007) Long story short: the serotonin transporter in emotion regulation and social cognition. Nat Neurosci 10:1103-1109. CrossRef Medline

Celada P, Puig MV, Casanovas JM, Guillazo G, Artigas F (2001) Control of dorsal raphe serotonergic neurons by the medial prefrontal cortex: involvement of serotonin-1A, GABA(A), and glutamate receptors. J Neurosci 21:9917-9929. Medline

Charuvastra A, Cloitre M (2008) Social bonds and posttraumatic stress disorder. Annu Rev Psychol 59:301-328. CrossRef Medline

Chattopadhyaya B, Di Cristo G, Higashiyama H, Knott GW, Kuhlman SJ, Welker E, Huang ZJ (2004) Experience and activity-dependent maturation of perisomatic GABAergic innervation in primary visual cortex during a postnatal critical period. J Neurosci 24:9598-9611. CrossRef Medline

Chiba T, Kayahara T, Nakano K (2001) Efferent projections of infralimbic and prelimbic areas of the medial prefrontal cortex in the Japanese monkey, Macaca fuscata. Brain Res 888:83-101. CrossRef Medline

Chow BY, Han X, Dobry AS, Qian X, Chuong AS, Li M, Henninger MA, Belfort GM, Lin Y, Monahan PE, Boyden ES (2010) High-performance genetically targetable optical neural silencing by light-driven proton pumps. Nature 463:98-102. CrossRef Medline

Crawford LK, Craige CP, Beck SG (2010) Increased intrinsic excitability of lateral wing serotonin neurons of the dorsal raphe: a mechanism for selective activation in stress circuits. J Neurophysiol 103:2652-2663. CrossRef Medline

Crawford LK, Craige CP, Beck SG (2011) Glutamatergic input is selectively increased in dorsal raphe subfield 5-HT neurons: role of morphology, topography and selective innervation. Eur J Neurosci 34:1794-1806. CrossRef Medline

Crawford LK, Rahman SF, Beck SG (2013) Social stress alters inhibitory synaptic input to distinct subpopulations of raphe serotonin neurons. ACS Chem Neurosci 4:200-209. CrossRef Medline

Cusi AM, Nazarov A, Holshausen K, Macqueen GM, McKinnon MC (2012) Systematic review of the neural basis of social cognition in patients with mood disorders. J Psychiatry Neurosci 37:154-169. CrossRef Medline

Espallergues J, Teegarden SL, Veerakumar A, Boulden J, Challis C, Jochems J, Chan M, Petersen T, Deneris E, Matthias P, Hahn CG, Lucki I, Beck SG, Berton O (2012) HDAC6 regulates glucocorticoid receptor signaling in serotonin pathways with critical impact on stress resilience. J Neurosci 32:4400-4416. CrossRef Medline

Ettenberg A, Ofer OA, Mueller CL, Waldroup S, Cohen A, Ben-Shahar O (2011) Inactivation of the dorsal raphé nucleus reduces the anxiogenic response of rats running an alley for intravenous cocaine. Pharmacol Biochem Behav 97:632-639. CrossRef Medline

Freedman LJ, Insel TR, Smith Y (2000) Subcortical projections of area 25 (subgenual cortex) of the macaque monkey. J Comp Neurol 421:172-188. CrossRef Medline

Fu W, Le Maître E, Fabre V, Bernard JF, David Xu ZQ, Hökfelt T (2010) Chemical neuroanatomy of the dorsal raphe nucleus and adjacent struc- 
tures of the mouse brain. J Comp Neurol 518:3464-3494. CrossRef Medline

Golden SA, Covington HE 3rd, Berton O, Russo SJ (2011) A standardized protocol for repeated social defeat stress in mice. Nat Protoc 6:1183-1191. CrossRef Medline

Hamani C, Diwan M, Macedo CE, Brandão ML, Shumake J, GonzalezLima F, Raymond R, Lozano AM, Fletcher PJ, Nobrega JN (2010) Antidepressant-like effects of medial prefrontal cortex deep brain stimulation in rats. Biol Psychiatry 67:117-124. CrossRef Medline

Hamani C, Machado DC, Hipólide DC, Dubiela FP, Suchecki D, Macedo CE, Tescarollo F, Martins U, Covolan L, Nobrega JN (2012) Deep brain stimulation reverses anhedonic-like behavior in a chronic model of depression: role of serotonin and brain derived neurotrophic factor. Biol Psychiatry 71:30-35. CrossRef Medline

Hames JL, Hagan CR, Joiner TE (2013) Interpersonal processes in depression. Annu Rev Clin Psychol 9:355-377. CrossRef Medline

Hou C, Xue L, Feng J, Zhang L, Wang Y, Chen L, Wang T, Zhang QJ, Liu J (2012) Unilateral lesion of the nigrostriatal pathway decreases the response of GABA interneurons in the dorsal raphe nucleus to 5-HT(1A) receptor stimulation in the rat. Neurochem Int 61:1344-1356. CrossRef Medline

Jankowski MP, Sesack SR (2004) Prefrontal cortical projections to the rat dorsal raphe nucleus: ultrastructural features and associations with serotonin and gamma-aminobutyric acid neurons. J Comp Neurol 468:518529. CrossRef Medline

Krishnan V, Han MH, Graham DL, Berton O, Renthal W, Russo SJ, Laplant Q, Graham A, Lutter M, Lagace DC, Ghose S, Reister R, Tannous P, Green TA, Neve RL, Chakravarty S, Kumar A, Eisch AJ, Self DW, Lee FS, Tamminga CA, Cooper DC, Gershenfeld HK, Nestler EJ (2007) Molecular adaptations underlying susceptibility and resistance to social defeat in brain reward regions. Cell 131:391-404. CrossRef Medline

Krishnan V, Berton O, Nestler E (2008) The use of animal models in psychiatric research and treatment. Am J Psychiatry 165:1109. CrossRef Medline

Kudryavtseva NN, Bakshtanovskaya IV, Koryakina LA (1991) Social model of depression in mice of C57BL/6J strain. Pharmacol Biochem Behav 38:315-320. CrossRef Medline

Kumar S, Black SJ, Hultman R, Szabo ST, DeMaio KD, Du J, Katz BM, Feng G, Covington HE 3rd, Dzirasa K (2013) Cortical control of affective networks. J Neurosci 33:1116-1129. CrossRef Medline

Liu C, Maejima T, Wyler SC, Casadesus G, Herlitze S, Deneris ES (2010) Pet-1 is required across different stages of life to regulate serotonergic function. Nat Neurosci 13:1190-1198. CrossRef Medline

Liu R, Jolas T, Aghajanian G (2000) Serotonin 5-HT(2) receptors activate local GABA inhibitory inputs to serotonergic neurons of the dorsal raphe nucleus. Brain Res 873:34-45. CrossRef Medline

Madisen L, Zwingman TA, Sunkin SM, Oh SW, Zariwala HA, Gu H, Ng LL, Palmiter RD, Hawrylycz MJ, Jones AR, Lein ES, Zeng H (2010) A robust and high-throughput Cre reporting and characterization system for the whole mouse brain. Nat Neurosci 13:133-140. CrossRef Medline

Malatynska E, Rapp R, Harrawood D, Tunnicliff G (2005) Submissive behavior in mice as a test for antidepressant drug activity. Pharmacol Biochem Behav 82:306-313. CrossRef Medline

Mattis J, Tye KM, Ferenczi EA, Ramakrishnan C, O’Shea DJ, Prakash R, Gunaydin LA, Hyun M, Fenno LE, Gradinaru V, Yizhar O, Deisseroth K (2012) Principles for applying optogenetic tools derived from direct comparative analysis of microbial opsins. Nat Methods 9:159-172. CrossRef Medline

McKenna JT, Yang C, Franciosi S, Winston S, Abarr KK, Rigby MS, Yanagawa Y, McCarley RW, Brown RE (2013) Distribution and intrinsic membrane properties of basal forebrain GABAergic and parvalbumin neurons in the mouse. J Comp Neurol 521:1225-1250. CrossRef Medline

Meyer-Lindenberg A, Tost H (2012) Neural mechanisms of social risk for psychiatric disorders. Nat Neurosci 15:663-668. CrossRef Medline

Miller EK, Cohen JD (2001) An integrative theory of prefrontal cortex function. Annu Rev Neurosci 24:167-202. CrossRef Medline

Passamonti L, Crockett MJ, Apergis-Schoute AM, Clark L, Rowe JB, Calder AJ, Robbins TW (2012) Effects of acute tryptophan depletion on prefrontal-amygdala connectivity while viewing facial signals of aggression. Biol Psychiatry 71:36-43. CrossRef Medline

Paul ED, Hale MW, Lukkes JL, Valentine MJ, Sarchet DM, Lowry CA (2011) Repeated social defeat increases reactive emotional coping behavior and alters functional responses in serotonergic neurons in the rat dorsal raphe nucleus. Physiol Behav 104:272-282. CrossRef Medline

Penn JK, Zito MF, Kravitz EA (2010) A single social defeat reduces aggression in a highly aggressive strain of Drosophila. Proc Natl Acad Sci U S A 107:12682-12686. CrossRef Medline

Phan KL, Coccaro EF, Angstadt M, Kreger KJ, Mayberg HS, Liberzon I, Stein MB (2013) Corticolimbic brain reactivity to social signals of threat before and after sertraline treatment in generalized social phobia. Biol Psychiatry 73:329-336. CrossRef Medline

Pollack MH (2005) Comorbid anxiety and depression. J Clin Psychiatry 66: 22-29. Medline

Raleigh MJ, McGuire MT, Brammer GL, Pollack DB, Yuwiler A (1991) Serotonergic mechanisms promote dominance acquisition in adult male vervet monkeys. Brain Res 559:181-190. CrossRef Medline

Roche M, Commons KG, Peoples A, Valentino RJ (2003) Circuitry underlying regulation of the serotonergic system by swim stress. J Neurosci 23:970-977. Medline

Rogers RD (2011) The roles of dopamine and serotonin in decision making: evidence from pharmacological experiments in humans. Neuropsychopharmacology 36:114-132. CrossRef Medline

Roiser JP, Elliott R, Sahakian BJ (2012) Cognitive mechanisms of treatment in depression. Neuropsychopharmacology 37:117-136. CrossRef Medline

Roy M, Shohamy D, Wager TD (2012) Ventromedial prefrontal-subcortical systems and the generation of affective meaning. Trends Cogn Sci 16:147156. CrossRef Medline

Scott MM, Wylie CJ, Lerch JK, Murphy R, Lobur K, Herlitze S, Jiang W, Conlon RA, Strowbridge BW, Deneris ES (2005) A genetic approach to access serotonin neurons for in vivo and in vitro studies. Proc Natl Acad Sci U S A 102:16472-16477. CrossRef Medline

Slavich GM, O’Donovan A, Epel ES, Kemeny ME (2010) Black sheep get the blues: a psychobiological model of social rejection and depression. Neurosci Biobehav Rev 35:39-45. CrossRef Medline

Sunkin SM, Ng L, Lau C, Dolbeare T, Gilbert TL, Thompson CL, Hawrylycz M, Dang C (2013) Allen Brain Atlas: an integrated spatio-temporal portal for exploring the central nervous system. Nucleic Acids Res 41:D996D1008. CrossRef Medline

Takahashi A, Shimamoto A, Boyson CO, DeBold JF, Miczek KA (2010) $\mathrm{GABA}(\mathrm{B})$ receptor modulation of serotonin neurons in the dorsal raphe nucleus and escalation of aggression in mice. J Neurosci 30:11771-11780. CrossRef Medline

Takahashi A, Schilit AN, Kim J, Debold JF, Koide T, Miczek KA (2012) Behavioral characterization of escalated aggression induced by GABA(B) receptor activation in the dorsal raphe nucleus. Psychopharmacology 224: 155-166. CrossRef Medline

Taniguchi H, He M, Wu P, Kim S, Paik R, Sugino K, Kvitsiani D, Kvitsani D, Fu Y, Lu J, Lin Y, Miyoshi G, Shima Y, Fishell G, Nelson SB, Huang ZJ (2011) A resource of Cre driver lines for genetic targeting of GABAergic neurons in cerebral cortex. Neuron 71:995-1013. CrossRef Medline

Todorov A (2008) Evaluating faces on trustworthiness: an extension of systems for recognition of emotions signaling approach/avoidance behaviors. Ann N Y Acad Sci 1124:208-224. CrossRef Medline

Tsankova NM, Berton O, Renthal W, Kumar A, Neve RL, Nestler EJ (2006) Sustained hippocampal chromatin regulation in a mouse model of depression and antidepressant action. Nat Neurosci 9:519-525. CrossRef Medline

Varga V, Székely AD, Csillag A, Sharp T, Hajós M (2001) Evidence for a role of GABA interneurones in the cortical modulation of midbrain 5-hydroxytryptamine neurones. Neuroscience 106:783-792. CrossRef Medline

Varga V, Kocsis B, Sharp T (2003) Electrophysiological evidence for convergence of inputs from the medial prefrontal cortex and lateral habenula on single neurons in the dorsal raphe nucleus. Eur J Neurosci 17:280-286. CrossRef Medline

Volman I, Roelofs K, Koch S, Verhagen L, Toni I (2011) Anterior prefrontal cortex inhibition impairs control over social emotional actions. Curr Biol 21:1766-1770. CrossRef Medline

Warden MR, Selimbeyoglu A, Mirzabekov JJ, Lo M, Thompson KR, Kim SY, Adhikari A, Tye KM, Frank LM, Deisseroth K (2012) A prefrontal cortex-brainstem neuronal projection that controls response to behavioural challenge. Nature 492:428-432. CrossRef Medline

Wierenga CJ, Müllner FE, Rinke I, Keck T, Stein V, Bonhoeffer T (2010) 
Molecular and electrophysiological characterization of GFP-expressing CA1 interneurons in GAD65-GFP mice. PLoS One 5:e15915. CrossRef Medline
Young SN (2013) The effect of raising and lowering tryptophan levels on human mood and social behaviour. Philos Trans R Soc Lond B Biol Sci 368:20110375. CrossRef Medline 